\title{
A Novel Decision Support System Based on Fuzzy Multi Criteria Decision Making for Optimizing Machining Parameters
}

DOI:10.36909/jer.13567

\author{
Muhammed Ordu* and Yusuf Fedai* \\ * Osmaniye Korkut Ata University, Faculty of Engineering, Department of Industrial Engineering, 80000, \\ Osmaniye, Turkey \\ Corresponding Author: muhammedordu@osmaniye.edu.tr
}

\begin{abstract}
The aim of this study is to develop a novel decision support system, which has never been developed yet, in order to optimize machining parameters. We combine the three distinct methods: experimental design and analysis, fuzzy data envelopment analysis (DEA) and fuzzy analytical hierarchy process (AHP). Firstly, a full factorial experiment including four factors and three levels is carried out. We take into account cutting speed, feed rate, depth of cut and number of cutting tool inserts as factors. The following three outputs are selected: Material Removal Rate, Machining Time and Surface Roughness. Secondly, a total of 23 experiments are determined as efficient decision-making units using fuzzy DEA with super efficiency method. Finally, a fuzzy AHP approach is conducted to rank the efficient experiments among each other. In conclusion, the results show that the Fuzzy DEA-Fuzzy AHP and the Fuzzy DEA with Super Efficiency generate clearly different rankings of experiments and Fuzzy DEA-Fuzzy AHP Approach has outperformed Fuzzy DEA with Super Efficiency Approach. The results highlight the importance of taking into account the expert opinions in the decision-making processes.
\end{abstract}

Key words: decision support system; experimental analysis; fuzzy analytical hierarchy process; fuzzy data envelopment analysis; fuzzy multi criteria decision making; machining.

\section{INTRODUCTION}

AISI 4140 steel is one of the most commonly used alloys in many different industries, 
especially automotive and aerospace, since it has a variety of characteristic features, for example, weldability, good formability, and excellent corrosion resistance properties and high strength. In addition, machinery, parts and apparatus, agricultural vehicles, a number of products used in the defense areas and the petroleum and derivatives industry are various area of usage of AISI 4140 steel. Machining operations are performed on the material with various methods since it has a very wide area of use (Şahinoğlu and Rafighi (2020), Gürbüz and Gönülaçar (2020), Schwalm et al. (2020) and Lubis et al. (2020)).

Cost, time and quality are the most important factors affecting the productivity in manufacturing. In order to adapt to new technologies and survive in the competitive markets, the variables that affect these factors must be controlled. CNC milling is one of the traditional machining methods frequently used in the manufacturing and other industrial sectors. Many studies have concentrated on cutting parameters to improve the quality of machining processes in milling. The performance of the milling mainly depends on the selection of the most appropriate input parameters to optimize various objective functions, such as maximizing material removal rate (MRR), minimizing machining time (Tm) and surface roughness (Ra) (Kumar and Verma, 2020). Most of the deformation occurring between tools and materials during machining causes some difficulties to achieve the desired optimization goals due to the result of the interaction of many factors. In order to overcome these problems, researchers have suggested various approaches to optimize cause-effect relationships between various factors and targeted product characteristics with multiple responses (Al-Refaie et al., 2014).

There exist a number of studies on optimization of machining parameters in the literature. The studies are designed according to experimental design methods (i.e. Full factorial, Taguchi and so on) and then, main and interaction effects are analyzed, for example Fedai et al. (2018) and Kahraman et al. (2018). In general, single and multiple response optimization studies are conducted, for example Ananthakumar et al. (2019), Sharma et al. (2019) and Basar et al. 
(2019). However, fuzzy environment has not been obviously taken into account. On the other hand, multiple replications are performed for each experiment in the studies. Thus, more than one values are generated for each output. In this case, it reveals that the study does not have exact values and has an average and standard deviation value. These circumstances suggest that such studies should use the fuzzy logic approach to overcome this type of uncertainties. In a number of studies, the optimum values of the input parameters are determined either by data envelopment analysis or by multi-criteria decision making methods (i.e. TOPSIS, PROMETHEE or AHP) using the inputs and outputs obtained from the experimental analysis, for example Manoj et al. (2018), Chakraborty et al. (2019), Phan and Muthuramalingam (2020), Naik et al. (2020) and Basar et al. (2020). In other studies, the criterion weights are calculated using AHP method and then, the weights are embedded into other multi-criteria decision making methods, for example Singaravel and Selvaraj (2015), Nadda et al. (2020) and Kumar and Verma (2020). However, our study differs from the literature due to the following aspects: 1) A total of 81 experiments were conducted with full factorial experimental analysis. Three replications for surface roughness were performed for each experiment and output values were obtained, 2) In our optimization stages, the uncertainty and fuzzy environment caused by outputs' different values obtained from the replications were taken into account, 3) Efficient experiments determined by the Fuzzy DEA approach were optimized by using the Fuzzy AHP method based on expert opinions. No study regarding the optimization of the machining parameters has applied such this approach. But this study fills this gap in the literature.

The remaining of the paper is organized as follows: Section 2 describes the proposed decision support system and explains the methodologies (i.e. experimental design and analysis, fuzzy data envelopment analysis and fuzzy analytical hierarchy process) in greater details. Section 3 discusses the results and Section 4 concludes the study, respectively.

\section{THE PROPOSED DECISION SUPPORT SYSTEM}

In this study, we combined the following three methods to develop a decision support 
system (see Figure 1) in order to optimize machining parameters: Experimental design and analysis, fuzzy data envelopment analysis (DEA) and fuzzy analytical hierarchy process (AHP). Firstly, a full factorial experiment $\left(3^{4}=81\right)$ was designed. This experimental design consists of four factors (i.e. cutting speed, feed rate, depth of cut and number of cutting tool inserts) and three levels. Three output parameters (i.e. material removal rate, surface roughness and machining time) were measured. Secondly, all inputs and generated outputs in the experimental design and analysis were then fed into the fuzzy data envelopment analysis models. Thus, the efficient Decision Making Units (i.e. experiments) were determined. Finally, the efficient experiments were investigated in terms of multi criteria decision making problem to optimize multi-response problem and rank the alternatives by taking into account expert opinions. Thus, this decision support system is able to assess and compare the machining parameters in fuzzy environment. Briefly stated, the main contribution of the study is to develop a decision support system by integrating three distinct techniques mentioned above to determine optimum parameters in machining all materials (i.e. steels, nanocomposite materials). This novel hybrid approach enables to specify the optimum combination of factors and levels amongst all experiments of the full factorial experimental design.

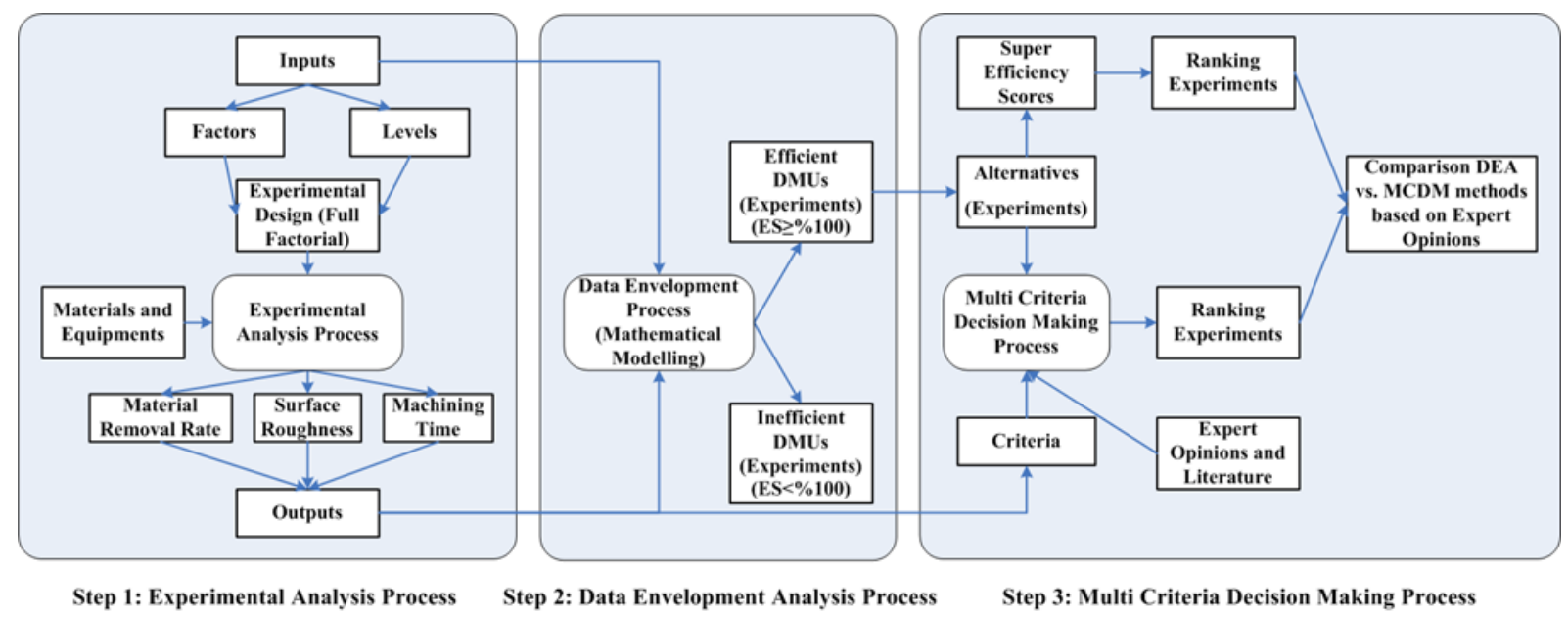

Figure 1 The structure of the proposed decision support system 


\section{STEP 1: EXPERIMENTAL ANALYSIS PROCESS}

AISI 4140 steel used in the study is a material that is highly resistant to friction, impact and cracking due to the intense carbon in its composition. Due to this feature, it has an intensive usage area in automotive, aircraft, machine tools and many machine parts (i.e. axles made for different purposes and shafts and gears).

The material used in the experiments was cut to 260x150x25 mm with an aqueous saw and made suitable for the study. In order to eliminate the effects of oxides and residues on the surface of the part on the test results, the material was primarily subjected to a surface milling process. Cutting experiments were carried out in CNC vertical machining center of SPINNER MVC1000 (see Fig. 2a). In the milling process, R 390-11 T308M-PM 1030 PVD and TiAlN + TiN coated carbide cutting tool and R 390-020B20-11M tool holder from Sandvik Inc. were also used.

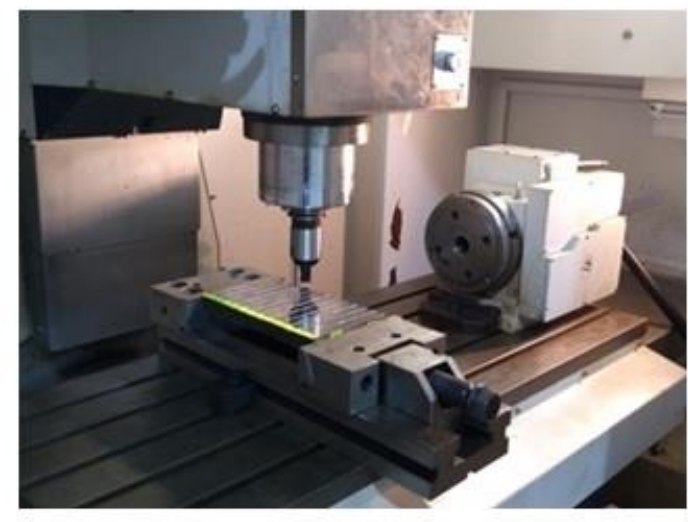

(a)

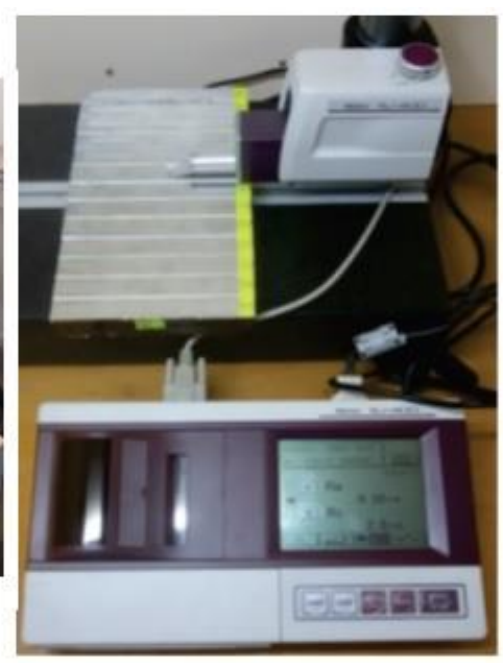

(b)

Figure 2 a) The experimental setup, b) The portable device for measuring surface roughness

In milling experiments, cutting parameters and levels used in the milling of the AISI 4140 steel are as follows: Cutting speed $(175,250$ and $325 \mathrm{~m} / \mathrm{min})$, Feed rate $(0.08,0.12$ and 0.16 
$\mathrm{mm} / \mathrm{rev})$, Depth of cut $(0.5,1$ and $1.5 \mathrm{~mm})$ and Number of cutting tool inserts $(1,2$ and 3 units)

In the experiments, the followings were considered as outputs, i.e. Material Removal Rate (see Eq. 1 for the formula), Machining Time (see Eq. 2 for the formula) and MinimumMaximum values of Surface Roughness. Surface roughness was measured with the MITUTOYO SJ-400 portable surface roughness device (see Fig. 2b).

$M R R=w d f_{r}$

where $M R R$ is material removal rate $\left(\mathrm{mm}^{3} / \mathrm{min}\right), w$ is width of cut $(\mathrm{mm}), d$ is depth of cut (mm) and $f_{r}$ is feed rate $(\mathrm{mm} / \mathrm{min})$ (Groover, 2010).

$T_{m}=\frac{L+A}{f_{r}}$

where $\mathrm{Tm}$ is machining time ( $\mathrm{min}), \mathrm{L}$ is length of cut $(\mathrm{mm})$ and $\mathrm{A}$ is approach distance $(\mathrm{mm})$ (Groover, 2010).

\section{STEP 2: DATA ENVELOPMENT ANALYSIS PROCESS}

Our second step is to determine the efficient experiments amongst all experiments and to do this, we used data envelopment analysis (DEA) method. DEA method is an effective method of comparing decision making units in terms of relative effectiveness (Wen and $\mathrm{Li}, 2009$ ). Liu and Chuang (2009) states a number of situations in the use of DEA method cause complexity and difficulty. For example, difficulties in measuring or imprecise numbers of inputs or outputs. If desired to get reliable results from DEA, the exact values of inputs and outputs should be obtained. However, obtaining exact numbers or values from a number of systems, processes or experiments might be very difficult. In this case, fuzzy environment conditions come into play. We have used fuzzy DEA method due to that the output (i.e. surface roughness) has the fuzzy numbers because of the replications of experiments. The efficiency scores of the all experiments are given in Table 1. 
Table 1: Efficiency scores: E: Experiment

\begin{tabular}{|c|c|c|c|c|c|}
\hline Experiments & $\begin{array}{c}\text { Efficiency Scores } \\
(\%)\end{array}$ & Experiments & $\begin{array}{c}\text { Efficiency Scores } \\
(\%)\end{array}$ & Experiments & $\begin{array}{c}\text { Efficiency Scores } \\
(\%)\end{array}$ \\
\hline E1 & 100.00 & E66 & 99.87 & E41 & 87.95 \\
\hline E2 & 100.00 & E69 & 99.83 & E14 & 87.03 \\
\hline E21 & 100.00 & E51 & 99.65 & E9 & 86.82 \\
\hline E27 & 100.00 & E48 & 99.51 & E33 & 86.63 \\
\hline E28 & 100.00 & E43 & 99.49 & E13 & 86.61 \\
\hline E32 & 100.00 & E77 & 99.07 & E42 & 86.46 \\
\hline E37 & 100.00 & E74 & 99.06 & E6 & 86.24 \\
\hline E54 & 100.00 & E59 & 96.20 & E30 & 85.38 \\
\hline E55 & 100.00 & E35 & 96.04 & E68 & 84.99 \\
\hline E56 & 100.00 & E25 & 95.73 & E15 & 84.86 \\
\hline E57 & 100.00 & $\mathrm{E} 4$ & 95.47 & E5 & 84.84 \\
\hline E58 & 100.00 & E10 & 94.68 & E38 & 84.68 \\
\hline E60 & 100.00 & E67 & 94.39 & E36 & 84.55 \\
\hline E61 & 100.00 & $\mathrm{E} 40$ & 94.24 & E46 & 84.36 \\
\hline E62 & 100.00 & E16 & 92.04 & E71 & 84.32 \\
\hline E63 & 100.00 & E20 & 91.84 & E52 & 83.71 \\
\hline E64 & 100.00 & E3 & 91.31 & E18 & 83.35 \\
\hline E70 & 100.00 & E39 & 90.47 & E53 & 82.73 \\
\hline E73 & 100.00 & E12 & 90.16 & E8 & 82.09 \\
\hline E75 & 100.00 & E19 & 90.11 & E49 & 80.92 \\
\hline E78 & 100.00 & E11 & 89.98 & E17 & 80.38 \\
\hline E79 & 100.00 & E47 & 89.64 & E34 & 79.87 \\
\hline E81 & 100.00 & E29 & 89.60 & E50 & 79.77 \\
\hline E72 & 99.99 & E23 & 89.49 & E26 & 79.20 \\
\hline E80 & 99.99 & E7 & 89.45 & E65 & 77.96 \\
\hline E24 & 99.95 & E45 & 89.32 & E31 & 76.08 \\
\hline E76 & 99.95 & E22 & 88.20 & E44 & 73.37 \\
\hline
\end{tabular}

\section{STEP 3: MULTI CRITERIA DECISION MAKING PROCESS}

The Step 3 in our study includes the application of the expert opinion-based multi criteria decision making process as seen in Figure 3. At this Step, fuzzy analytical hierarchy process was carried out to rank the efficient experiments, which were calculated in the previous step, based on the opinions of a number of experts consisting of mechanical and industrial engineers. Fuzzy AHP method is an extension version of Analytical Hierarchy Process method developed by Saaty (1980). It consists of the combination of AHP method and the fuzzy set theory (Duran and Aguilo, 2008). In the first stage, construction of hierarchy for the solution of the problem. Our structure of the hierarchy is presented in Figure 3. In the second stage, the fuzzy comparison matrix is developed, and fuzzy weight vector is established. Ayag and Ozdemir (2006) states that the triangular fuzzy numbers are used to develop the matrix. 


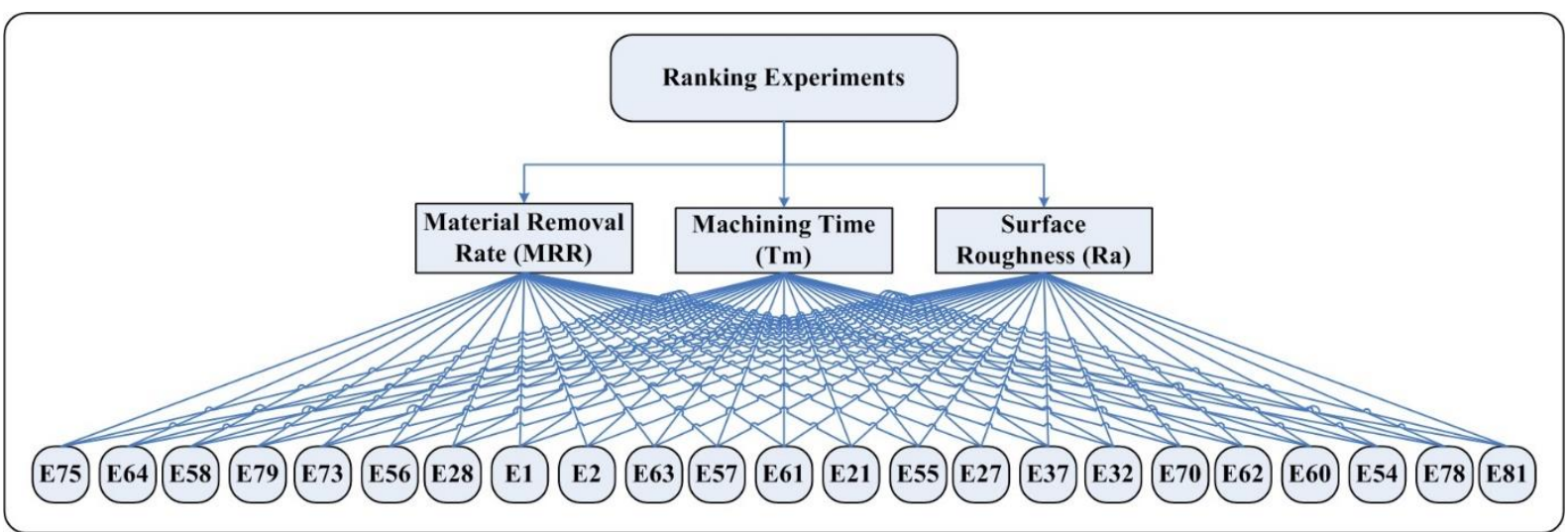

Figure 3 The structure of the MCDM problem

The fuzzy pairwise comparison matrix, fuzzy weights and normalized weights for the main criteria are given as an example in Table 2. Fedai et al. (2018) stated surface roughness is an important factor affecting the machinability of a material. It is also one of the common problems encountered on surfaces after machining. Therefore, it affects the quality of the material. Other factors affecting the quality used in this study are material removal rate and machining time. It can be understood from Eq. (1) and (2) that they are related and inversely proportional to each other. However, the surface roughness is very important than these two criteria in terms of manufacturing material with the desired quality. Due to these reasons, the criteria are weighted as in Table 2. We also prepared the fuzzy pairwise comparison matrix for the all criteria.

Table 2 Pairwise comparison matrix of the criteria

\begin{tabular}{|c|c|c|c|c|c|c|c|}
\hline Response & MRR & Tm & Ra & \multicolumn{3}{|c|}{ Fuzzy Weights } & Normalized Weights \\
\hline MRR & 1 & $\widetilde{1}$ & $\widetilde{8^{-1}}$ & 0.089 & 0.093 & 0.097 & 0.100 \\
\hline Tm & $\widetilde{1^{-1}}$ & 1 & $\widetilde{8^{-1}}$ & 0.089 & 0.093 & 0.097 & 0.100 \\
\hline Ra & $\widetilde{8}$ & $\widetilde{8}$ & 1 & 0.681 & 0.745 & 0.805 & 0.800 \\
\hline
\end{tabular}

In Table 3, we calculated geometric means for all experiments after the establishment of fuzzy comparison matrix. After that, fuzzy weights for each alternative are determined and then, we averaged the fuzzy weights. Finally, the normalization procedure was carried out. We applied the procedure of fuzzy AHP for all criteria (i.e. MRR, Tm and Ra). 
Table 3 Geometric mean, fuzzy weights and normalized weights for the first criterion (i.e. Material Removal Rate)

\begin{tabular}{|c|c|c|c|c|c|c|c|c|}
\hline Experiments & \multicolumn{3}{|c|}{ Geometric Mean } & \multicolumn{3}{|c|}{ Fuzzy Weights } & Average & $\begin{array}{c}\text { Normalized } \\
\text { Weights }\end{array}$ \\
\hline E75 & 1.269 & 1.882 & 2.295 & 24.311 & 52.501 & 92.488 & 56.433 & 0.061134 \\
\hline E64 & 0.426 & 0.602 & 0.918 & 8.155 & 16.788 & 37.007 & 20.650 & 0.022370 \\
\hline E58 & 0.554 & 0.800 & 1.439 & 10.610 & 22.309 & 57.995 & 30.305 & 0.032829 \\
\hline E79 & 1.231 & 1.882 & 2.437 & 23.589 & 52.501 & 98.234 & 58.108 & 0.062948 \\
\hline E73 & 0.554 & 0.800 & 1.439 & 10.610 & 22.309 & 57.995 & 30.305 & 0.032829 \\
\hline E56 & 0.554 & 0.800 & 1.439 & 10.610 & 22.309 & 57.995 & 30.305 & 0.032829 \\
\hline E28 & 0.230 & 0.291 & 0.382 & 4.402 & 8.126 & 15.376 & 9.301 & 0.010076 \\
\hline E1 & 0.176 & 0.206 & 0.283 & 3.371 & 5.741 & 11.418 & 6.843 & 0.007413 \\
\hline E2 & 0.306 & 0.394 & 0.531 & 5.853 & 10.988 & 21.403 & 12.748 & 0.013810 \\
\hline E63 & 1.269 & 1.882 & 2.589 & 24.311 & 52.501 & 104.337 & 60.383 & 0.065413 \\
\hline E57 & 0.741 & 1.106 & 1.798 & 14.197 & 30.849 & 72.467 & 39.171 & 0.042433 \\
\hline E61 & 0.719 & 1.106 & 1.745 & 13.775 & 30.849 & 70.316 & 38.313 & 0.041504 \\
\hline E21 & 0.777 & 1.140 & 1.594 & 14.891 & 31.793 & 64.237 & 36.974 & 0.040053 \\
\hline E55 & 0.289 & 0.383 & 0.557 & 5.536 & 10.691 & 22.450 & 12.892 & 0.013966 \\
\hline E27 & 1.308 & 1.882 & 2.668 & 25.055 & 52.501 & 107.529 & 61.695 & 0.066834 \\
\hline E37 & 0.344 & 0.439 & 0.623 & 6.594 & 12.238 & 25.125 & 14.652 & 0.015872 \\
\hline E32 & 0.754 & 1.140 & 1.798 & 14.449 & 31.793 & 72.467 & 39.570 & 0.042865 \\
\hline E70 & 1.072 & 1.746 & 2.133 & 20.531 & 48.703 & 85.949 & 51.728 & 0.056036 \\
\hline E62 & 1.231 & 1.882 & 2.512 & 23.589 & 52.501 & 101.240 & 59.110 & 0.064033 \\
\hline E60 & 1.231 & 1.882 & 2.512 & 23.589 & 52.501 & 101.240 & 59.110 & 0.064033 \\
\hline E54 & 1.324 & 1.826 & 2.750 & 25.370 & 50.943 & 110.819 & 62.377 & 0.067573 \\
\hline E78 & 1.365 & 1.826 & 2.834 & 26.146 & 50.943 & 114.210 & 63.766 & 0.069078 \\
\hline E81 & 1.432 & 1.999 & 3.025 & 27.426 & 55.763 & 121.928 & 68.372 & 0.074067 \\
\hline Total & 19.157 & 27.895 & 40.302 & & & & 923.112 & 1.000000 \\
\hline Inverse & 0.052 & 0.036 & 0.025 & & & & & \\
\hline Increasing Order & 0.025 & 0.036 & 0.052 & & & & & \\
\hline
\end{tabular}

In the Fuzzy AHP methodology, consistency ratio of the matrix is calculated to control the results of the study and make sure whether the comparison is acceptable or not, by using Eq.

(3) and (4) (Duran and Aguilo, 2008).

$C I=\frac{\lambda_{\max }-n}{n-1}$

where $C I$ means consistency index, n represents the number of alternatives.

$C R=C I / R I$

where $C R$ means consistency ratio and $R I$ is random consistency index and developed by Saaty (1980). Table 4 shows the consistency ratios of all fuzzy comparison matrices in this 
study and therefore, all matrices are acceptable due to that the consistency ratios are less than 0.10 .

Table 4 Consistency Ratios

\begin{tabular}{|l|c|c|c|c|}
\hline $\begin{array}{l}\text { Fuzzy } \\
\text { Comparison } \\
\text { Matrix }\end{array}$ & $\boldsymbol{\lambda}_{\max }$ & $\begin{array}{c}\text { Consistency } \\
\text { Index (CI) }\end{array}$ & $\begin{array}{c}\text { Random } \\
\text { Consistency Index } \\
\text { (RI) }\end{array}$ & $\begin{array}{c}\text { Consistency } \\
\text { Ratio (CR) }\end{array}$ \\
\hline Main Criteria & 3.000 & 0.0000 & 0.5800 & 0.0000 \\
\hline For MRR & 23.304 & 0.0138 & 1.6526 & 0.0084 \\
\hline For Tm & 23.312 & 0.0142 & 1.6526 & 0.0086 \\
\hline For Ra & 23.333 & 0.0151 & 1.6526 & 0.0092 \\
\hline
\end{tabular}

In the third step, ranking all alternatives and selection of the best alternative. Table 5 gives the results of Fuzzy DEA - Fuzzy AHP along with the results from the Fuzzy DEA with Super Efficiency.

\section{RESULTS AND DISCUSSION}

We used Cutting Speed (m/min), Feed Rate (mm/rev), Depth of cut $(\mathrm{mm})$ and Cutting Tool Inserts (unit) as factor. We selected the following three outputs which have been widely preferred in the literature: Surface roughness $(\mu \mathrm{m})$, material removal rate $\left(\mathrm{mm}^{3} / \mathrm{min}\right)$ and machining time (min).

Table 5 Comparison of the results from Fuzzy DEA with Super Efficiency \& Fuzzy DEAFuzzy AHP. A: Cutting speed, B: Feed rate, C: Depth of cut and D: Cutting tool inserts

\begin{tabular}{|c|c|c|c|c|c|}
\hline \multicolumn{3}{|c|}{ Fuzzy DEA with Super Efficiency } & \multicolumn{3}{|c|}{ Fuzzy DEA - Fuzzy AHP } \\
\hline Combinations & Scores & Rank & Combinations & Scores & Rank \\
\hline$(\mathrm{E} 75) \mathrm{A}_{3} \mathrm{~B}_{3} \mathrm{C}_{2} \mathrm{D}_{3}$ & $130.88 \%$ & 1 & $(\mathrm{E} 64) \mathrm{A}_{3} \mathrm{~B}_{2} \mathrm{C}_{1} \mathrm{D}_{1}$ & $6.28 \%$ & 1 \\
\hline (E64) $\mathrm{A}_{3} \mathrm{~B}_{2} \mathrm{C}_{1} \mathrm{D}_{1}$ & $129.09 \%$ & 2 & $(\mathrm{E} 73) \mathrm{A}_{3} \mathrm{~B}_{3} \mathrm{C}_{1} \mathrm{D}_{1}$ & $6.24 \%$ & 2 \\
\hline$(\mathrm{E} 58) \mathrm{A}_{3} \mathrm{~B}_{1} \mathrm{C}_{2} \mathrm{D}_{1}$ & $123.08 \%$ & 3 & $(\mathrm{E} 58) \mathrm{A}_{3} \mathrm{~B}_{1} \mathrm{C}_{2} \mathrm{D}_{1}$ & $6.15 \%$ & 3 \\
\hline (E79) $\mathrm{A}_{3} \mathrm{~B}_{3} \mathrm{C}_{3} \mathrm{D}_{1}$ & $122.47 \%$ & 4 & $(\mathrm{E} 61) \mathrm{A}_{3} \mathrm{~B}_{1} \mathrm{C}_{3} \mathrm{D}_{1}$ & $6.12 \%$ & 4 \\
\hline$\left(\right.$ E73) $A_{3} B_{3} C_{1} D_{1}$ & $117.45 \%$ & 5 & $(\mathrm{E} 28) \mathrm{A}_{2} \mathrm{~B}_{1} \mathrm{C}_{1} \mathrm{D}_{1}$ & $5.88 \%$ & 5 \\
\hline$(\mathrm{E} 56) \mathrm{A}_{3} \mathrm{~B}_{1} \mathrm{C}_{1} \mathrm{D}_{2}$ & $117.17 \%$ & 6 & $(\mathrm{E} 55) \mathrm{A}_{3} \mathrm{~B}_{1} \mathrm{C}_{1} \mathrm{D}_{1}$ & $5.84 \%$ & 6 \\
\hline$(\mathrm{E} 28) \mathrm{A}_{2} \mathrm{~B}_{1} \mathrm{C}_{1} \mathrm{D}_{1}$ & $113.31 \%$ & 7 & $(\mathrm{E} 56) \mathrm{A}_{3} \mathrm{~B}_{1} \mathrm{C}_{1} \mathrm{D}_{2}$ & $5.79 \%$ & 7 \\
\hline$(\mathrm{E} 1) \mathrm{A}_{1} \mathrm{~B}_{1} \mathrm{C}_{1} \mathrm{D}_{1}$ & $112.01 \%$ & 8 & $(\mathrm{E} 79) \mathrm{A}_{3} \mathrm{~B}_{3} \mathrm{C}_{3} \mathrm{D}_{1}$ & $5.76 \%$ & 8 \\
\hline (E2) $\mathrm{A}_{1} \mathrm{~B}_{1} \mathrm{C}_{1} \mathrm{D}_{2}$ & $110.86 \%$ & 9 & $(\mathrm{E} 70) \mathrm{A}_{3} \mathrm{~B}_{2} \mathrm{C}_{3} \mathrm{D}_{1}$ & $5.58 \%$ & 9 \\
\hline (E63) $\mathrm{A}_{3} \mathrm{~B}_{1} \mathrm{C}_{3} \mathrm{D}_{3}$ & $110.23 \%$ & 10 & $(\mathrm{E} 37) \mathrm{A}_{2} \mathrm{~B}_{2} \mathrm{C}_{1} \mathrm{D}_{1}$ & $5.44 \%$ & 10 \\
\hline$(\mathrm{E} 57) \mathrm{A}_{3} \mathrm{~B}_{1} \mathrm{C}_{1} \mathrm{D}_{3}$ & $108.53 \%$ & 11 & $(\mathrm{E} 32) \mathrm{A}_{2} \mathrm{~B}_{1} \mathrm{C}_{1} \mathrm{D}_{2}$ & $5.20 \%$ & 11 \\
\hline (E61) $\mathrm{A}_{3} \mathrm{~B}_{1} \mathrm{C}_{3} \mathrm{D}_{1}$ & $108.43 \%$ & 12 & (E62) $A_{3} B_{1} C_{3} D_{2}$ & $5.03 \%$ & 12 \\
\hline$(\mathrm{E} 21) \mathrm{A}_{1} \mathrm{~B}_{3} \mathrm{C}_{1} \mathrm{D}_{3}$ & $105.70 \%$ & 13 & (E1) $\mathrm{A}_{1} \mathrm{~B}_{1} \mathrm{C}_{1} \mathrm{D}_{1}$ & $4.84 \%$ & 13 \\
\hline (E55) $\mathrm{A}_{3} \mathrm{~B}_{1} \mathrm{C}_{1} \mathrm{D}_{1}$ & $105.67 \%$ & 14 & $(\mathrm{E} 2) \mathrm{A}_{1} \mathrm{~B}_{1} \mathrm{C}_{1} \mathrm{D}_{2}$ & $4.62 \%$ & 14 \\
\hline (E27) $A_{1} B_{3} C_{3} D_{3}$ & $104.26 \%$ & 15 & $(\mathrm{E} 63) \mathrm{A}_{3} \mathrm{~B}_{1} \mathrm{C}_{3} \mathrm{D}_{3}$ & $3.01 \%$ & 15 \\
\hline$(\mathrm{E} 37) \mathrm{A}_{2} \mathrm{~B}_{2} \mathrm{C}_{1} \mathrm{D}_{1}$ & $102.61 \%$ & 16 & $(\mathrm{E} 60) \mathrm{A}_{3} \mathrm{~B}_{1} \mathrm{C}_{2} \mathrm{D}_{3}$ & $3.01 \%$ & 16 \\
\hline (E32) $\mathrm{A}_{2} \mathrm{~B}_{1} \mathrm{C}_{1} \mathrm{D}_{2}$ & $101.84 \%$ & 17 & $(\mathrm{E} 57) \mathrm{A}_{3} \mathrm{~B}_{1} \mathrm{C}_{1} \mathrm{D}_{3}$ & $2.72 \%$ & 17 \\
\hline$(\mathrm{E} 70) \mathrm{A}_{3} \mathrm{~B}_{2} \mathrm{C}_{3} \mathrm{D}_{1}$ & $101.03 \%$ & 18 & $(\mathrm{E} 81) \mathrm{A}_{3} \mathrm{~B}_{3} \mathrm{C}_{3} \mathrm{D}_{3}$ & $2.18 \%$ & 18 \\
\hline$(\mathrm{E} 62) \mathrm{A}_{3} \mathrm{~B}_{1} \mathrm{C}_{3} \mathrm{D}_{2}$ & $100.93 \%$ & 19 & $(\mathrm{E} 78) \mathrm{A}_{3} \mathrm{~B}_{3} \mathrm{C}_{1} \mathrm{D}_{3}$ & $2.17 \%$ & 19 \\
\hline
\end{tabular}




\begin{tabular}{|c|c|c|c|c|c|}
\hline (E60) $\mathrm{A}_{3} \mathrm{~B}_{1} \mathrm{C}_{2} \mathrm{D}_{3}$ & $100.76 \%$ & 20 & (E54) $\mathrm{A}_{2} \mathrm{~B}_{3} \mathrm{C}_{3} \mathrm{D}_{3}$ & $2.15 \%$ & 20 \\
\hline$(\mathrm{E} 54) \mathrm{A}_{2} \mathrm{~B}_{3} \mathrm{C}_{3} \mathrm{D}_{3}$ & $100.10 \%$ & 21 & (E75) $\mathrm{A}_{3} \mathrm{~B}_{3} \mathrm{C}_{2} \mathrm{D}_{3}$ & $2.12 \%$ & 21 \\
\hline$(\mathrm{E} 78) \mathrm{A}_{3} \mathrm{~B}_{3} \mathrm{C}_{1} \mathrm{D}_{3}$ & $100.00 \%$ & 22 & $(\mathrm{E} 27) \mathrm{A}_{1} \mathrm{~B}_{3} \mathrm{C}_{3} \mathrm{D}_{3}$ & $2.01 \%$ & 22 \\
\hline$(\mathrm{E} 81) \mathrm{A}_{3} \mathrm{~B}_{3} \mathrm{C}_{3} \mathrm{D}_{3}$ & $100.00 \%$ & 23 & $(\mathrm{E} 21) \mathrm{A}_{1} \mathrm{~B}_{3} \mathrm{C}_{1} \mathrm{D}_{3}$ & $1.86 \%$ & 23 \\
\hline
\end{tabular}

In the second step of our study, all of 81 experiments were optimized using fuzzy data envelopment analysis method on the basis of input-output relationship. 23 of these experiments (i.e. 28\%) were determined to be efficient experiments and all efficiency scores were between $73.37 \%$ and $100.00 \%$. Then, using the super efficiency method, these efficient experiments were ranked among themselves and the super efficiency scores were calculated to be between $100.00 \%$ and $130.88 \%$. The parameters of the most efficient experiment are Cutting Speed with $325 \mathrm{~m} / \mathrm{min}$, Feed Rate with $0.16 \mathrm{~mm} / \mathrm{rev}$, Depth of cut with $0.5 \mathrm{~mm}$ and 3 units of Cutting Tool Inserts. The cutting speed of the first six efficient experiments is 325 $\mathrm{m} / \mathrm{min}$ whereas the number of cutting tool inserts of two out of three of these experiments is 1 unit. Number of cutting tool inserts of 4 experiments which has the lowest efficiency score is 3 units (see Table 5).

In the third step of our study, these 23 efficient experiments were optimized by the fuzzy analytical hierarchy process method. The most important advantage of this step is the establishment of fuzzy comparison matrices by analysing and interpreting the experimental results by an expert team. Thus, the efficient experiments were compared based on expert opinion with each other in a fuzzy environment. The parameters of the most optimal experiment are as follows: Cutting Speed with $325 \mathrm{~m} / \mathrm{min}$, Feed Rate with $0.12 \mathrm{~mm} / \mathrm{rev}$, Depth of cut with $0.5 \mathrm{~mm}$ and 1 unit of Cutting Tool Inserts. The parameters of the last experiment are: Cutting Speed with $175 \mathrm{~m} / \mathrm{min}$, Feed Rate with $0.16 \mathrm{~mm} / \mathrm{rev}$, Depth of cut with $0.5 \mathrm{~mm}$ and 3 units of Cutting Tool Inserts. 1 unit Cutting Tool Inserts was used whereas Cutting Speed was $325 \mathrm{~m} / \mathrm{min}$ in the 8 of the first 9 experiments. Number of Cutting Tool 
Inserts for the last eight experiments is 3 units while the Feed Rate of the last six experiments is $0.16 \mathrm{~mm} / \mathrm{rev}$ (see Table 5 ).

In the literature, the studies that have been interested in the optimization of machining parameters (i.e. Basar et al. (2018), Fedai et al. (2018) and Sarikaya et al. (2015)) stated the minimum surface roughness value is obtained in the experiments which the cutting speed is the highest and the number of cutting tool inserts is 1. The Fuzzy DEA with Super Efficiency Approach developed in the second step of our study and the Fuzzy DEA-Fuzzy AHP Approach that we proposed in the third step also produced the results parallel to these results from the literature.

In addition, the Fuzzy DEA-Fuzzy AHP approach has made a more efficient ranking compared to the Fuzzy DEA with Super Efficiency Approach. Having a look at the first ten experiments in Table 5, it has been determined that the cutting speed is the highest in $70 \%$ of the experiments in the FDEA approach and in $80 \%$ of the experiments in the FDEA-FAHP approach. In addition, it is observed that the number of cutting tools is 1 in $60 \%$ of the experiments in the FDEA approach and $90 \%$ of the experiments in the FDEA-FAHP approach. Moreover, the combination of experiments with both the highest cutting speed and 1 cutting tool insert is determined to be $40 \%$ of the experiments in the FDEA approach and $70 \%$ in the FDEA-FAHP approach. All of these results show that the FDEA-FAHP approach we proposed in this study produces a better ranking.

According to Table 5, the results of Fuzzy DEA-Fuzzy AHP Approach and Fuzzy DEA with Super Efficiency clearly differ. The Fuzzy DEA with Super Efficiency determines the efficiency within the framework of input-output relationship and does not take into account any expert opinion. Also, neither criterion has a different weight. These situations can lead that we fail to make robust and reliable decisions in solving the problems we examine. At this point, the problem we are working on is evaluated by criteria with different priorities. Based 
on expert opinion, surface roughness is more important in this problem due to that it affects the quality of material (Fedai et al., 2018). Under these circumstances, giving equal importance to all criteria will allow misleading results to be produced as a result of the study.

\section{CONCLUSION}

In this study, we have developed a novel decision support system for optimizing the machining parameters. To do this, we have integrated three distinct techniques, i.e., experimental design and analysis, fuzzy DEA and fuzzy AHP methods. We have also compared the results of Fuzzy DEA with Super Efficiency and Fuzzy DEA-Fuzzy AHP. The results of two approach are clearly different based on the weights considered for the outputs and Fuzzy DEA-Fuzzy AHP Approach has outperformed Fuzzy DEA with Super Efficiency Approach. Therefore, this study has revealed the importance of expert opinions-based decision making process.

A number of users such as researchers studying on machining, managerial teams and engineers working in the industrial companies and decision makers in the research and development activities in this field can use this approach as a helpful decision support tool to determine optimum input parameters in theirs experimental studies. In addition, a more complex multi-response optimization will be able to carry out by considering more input parameters and levels at the same time. Thus, the related decision makers allow the managerial teams can obtain and facilitate the more efficient design of the manufacturing processes, and possible manufacturing defects can be avoided. Moreover, the machineability of the related materials will be able to improve by increasing the surface quality and reducing cost and time. The results obtained from this study will provide industrialists processing AISI 4140 steel with a more effective decision-making support in the selection of input and output parameters. 
A limitation of the study is that only fuzzy AHP methodology has been used as an expert opinion based-MCDM technique and is combined with the fuzzy DEA approach. However, AHP method has been integrated with other MCDM techniques (i.e., TOPSIS or PROMETHEE) in the literature to generate more accurate and reliable results. Another limitation is that the experiments are designed using only four factors and three levels although many factors and levels are used in the literature. The future work of this research can be to include more factors and levels in the experimental analysis process (i.e., Step 1). One of future research opportunity is to compare this approach with other MCDM techniques instead of using AHP method. On the other hand, criteria and alternatives have been weighted using only AHP method. Weighting can also be conducted using other methods such as entropy. At the same time, different output parameters such as cutting tool temperature and cutting force can be taken into account.

\section{REFERENCES}

Al-Refaie, A., Li, M.H., Jarbo, M., Yeh, C H.B. \& Nour, B. 2014. Imprecise data envelopment analysis model for robust design with multiple fuzzy quality responses. Advances in Production Engineering \& Management 9(2): 83-94.

Ananthakumar, K., Rajamani, D., Balasubramanian, E. \& Paulo Davim, J. 2019. Measurement and optimization of multi-response characteristics in plasma arc cutting of Monel 400TM using RSM and TOPSIS. Measurement 135: 725-737.

Ayag, Z. \& Ozdemir, R.G. 2006. A fuzzy AHP approach to evaluating machine tool alternatives. Journal of Intelligent Manufacturing 17: 179-190.

Başar, G., Kahraman, F. \& Önder, G.T. 2019. Mathematical Modeling and Optimization of Milling Parameters in AA 5083 Aluminum Alloy. European Mechanical Science 3(4): 159-163. 
Başar, G., Kırlı Akın, H. \& Kahraman, F. 2020. Analysis and Modeling of Thrust Force by using Response Surface Methodology in Drilling Nanocomposite. Gazi University Science Journal: PART:C: Design and Technology 8(2): 293-305.

Chakraborty, S., Chatterjee, P. \& Das, P.P. 2019. A DoE-TOPSIS method-based metamodel for parametric optimization of non-traditional machining processes. Journal of Modelling in Management 14(2): 430-455.

Duran, O. \& Aguilo, J. 2008. Computer-aided machine-tool selection based on a Fuzzy-AHP approach. Expert Systems with Applications 34: 1787-1794.

Groover, M. 2010. Principles of Modern Manufacturing. 4 ed. John Wiley \& Sons Inc.

Gürbüz, H. \& Gönülaçar, Y.E. 2020. Optimization and evaluation of dry and minimum quantity lubricating methods on machinability of AISI 4140 using Taguchi design and ANOVA. Proceedings of the Institution of Mechanical Engineers, Part C: Journal of Mechanical Engineering Science.

Fedai, Y., Kahraman, F., Kırlı Akın, H. \& Basar, G. 2018. Optimization of machining parameters in face milling using multi-objective Taguchi technique. Tehnički Glasnik 12(2): 104-108.

Kahraman, F., Başar, G., Koçoğlu, Z. \& Yeniyıl, E. 2018. Optimization of Cutting Parameters in Hole Machining Process by Using Multi-objective Taguchi Approach. Journal of Polytechnic 21(2): 283-290.

Kumar., J. \& Verma, R.K. 2020. Experimental Investigations and Multiple criteria Optimization during Milling of Graphene Oxide (GO) doped epoxy/CFRP Composites Using TOPSIS-AHP hybrid Module. FME Transactions 48: 628-635.

Li, S. \& Chuang, M. 2009. Fuzzy efficiency measures in fuzzy DEA/AR with application to university libraries. Expert Systems with Applications 36: 1105-1113.

Lubis, S., Rosehan, Darmaan, S. \& Indra, B. 2020. Tool Wear Analysis of Coated Carbide Tools on Cutting Force in Machining Process of AISI 4140 Steel. IOP Conf. Series: Materials Science and Engineering 852: 012083. 
Manoj, M., Jinu, G.R. \& Muthuramalingam, T. 2018. Multi Response Optimization of AWJM Process Parameters on Machining TiB2 Particles Reinforced A17075 Composite Using Taguchi-DEAR Methodology. Silicon 10: 2287-2293.

Nadda, R., Kumar, R., Singh, T., Chauhan, R., Patnaik, A. \& Gangil, B. 2018. Experimental investigation and optimization of cobalt bonded tungsten carbide composite by hybrid AHP-TOPSIS approach. Alexandria Engineering Journal 57: 3419-3428.

Naik., S., Das, S.R. \& Dhupal, D. 2020. Analysis. predictive modelling and multi-response optimization in electrical discharge machining of $\mathrm{Al}-22 \% \mathrm{SiC}$ metal matrix composite for minimization of surface roughness and hole overcut. Manufacturing Review 7(20): 1-28.

Phan, N.H. \& Muthuramalingam, T. 2020. Multi Criteria Decision Making of Vibration Assisted EDM Process Parameters on Machining Silicon Steel Using Taguchi-DEAR Methodology. Silicon 1-7.

Saaty, T.L. 1980. Analytic Herarchy Process. New York: McGraw Hill.

Sarıkaya, M., Yılmaz, V.\& Dilipak, H. 2015. Modeling and multi-response optimization of milling characteristics based on Taguchi and gray relational analysis. Proceedings of the Institution of Mechanical Engineers, Part B: Journal of Engineering Manufacture 230(6): 1049-1065.

Schwalm, J., Gerstenmeyer, M., Zanger, F. \& Schulze, V. 2020. Complementary Machining: Effect of tool types on tool wear and surface integrity of AISI 4140. Procedia CIRP 87: 89-94.

Sharma, V., Misra, J.P. \& Singhal, P. 2019. Optimization of process parameters on Combustor Material Using Taguchi \& MCDM Method in Electro-Discharge Machining (EDM). Materials Today: Proceedings 18: 2672-2678.

Singaravel, B. \& Selvaraj, T. 2015. Optimization of machining parameters in turning operation using combined TOPSIS and AHP method. Tehnički Vjesnik 22(6): 1475-1480.

Şahinoğlu, A. \& Rafighi, M. 2020. Investigation of Vibration, Sound Intensity, Machine Current and Surface Roughness Values of AISI 4140 During Machining on the Lathe. 
Arabian Journal for Science and Engineering 45: 765-778.

Wen, M. \& Li, H. 2009. Fuzzy data envelopment analysis (DEA): Model and ranking method. Journal of Computational and Applied Mathematics 223: 872-878. 